\title{
Health Hazards of Electromagnetic Radiation
}

\author{
Awn B. Rifai, Majed A. Hakami \\ Department of Information and Communication Technologies, Arab Open University, Jeddah, KSA \\ Email: awnrifai@hotmail.com
}

Received July 2014

\begin{abstract}
Electrical energy enters into the operation of a myriad industrial, scientific, medical, community and house equipment and appliances. The accompanying electromagnetic fields (EMFs) are partially transformed into radiation that affects human health. This research investigates the potential health hazards of radiation emanating from electric power lines. The research is based on studies by research organizations and on practical field measurements. The study includes investigation of electromagnetic radiation from high-voltage electric lines in inhabited areas in an urban environment, and provides some measurements in test locations in a typical city. The results are benchmarked against recommended safety levels.
\end{abstract}

\section{Keywords}

\section{Electromagnetic, Radiation, Environment, Health}

\section{Research Aims and Methodology}

Most people are unaware of the risks surrounding them as a consequence of electromagnetic radiation (EMR). Studies were conducted to find out whether the use of electrical devices and equipment endangers human health, and the extent of harm induced by continuous or long-term exposure to radiation. However, the results were far from being conclusive. This research attempts to investigate some potential effects of living close to, or using some types of electromagnetic radiation sources. This would contribute to increasing public awareness, taking measures to evade hazards, and regulating and monitoring the use of electricity. Radiation measurements were taken in some electric field zones in a typical city in order to quantify the investigation.

\section{Electricity Infrastructure}

A typical electric power generation and transmission system is depicted in Figure 1. The power lines can be underground cables or high-voltage tower cables. Most power transmission lines use high-voltage three-phase alternating current (AC). For greater efficiency across long distances, typically hundreds of kilometers, highvoltage direct-current (HVDC) technology is also used. Electricity is transmitted at high voltages (120 KV or above) in order to reduce the energy lost in long-distance transmission. Power is usually transmitted by overhead power lines. Underground power transmission has a higher cost and greater operational limitations but is some 


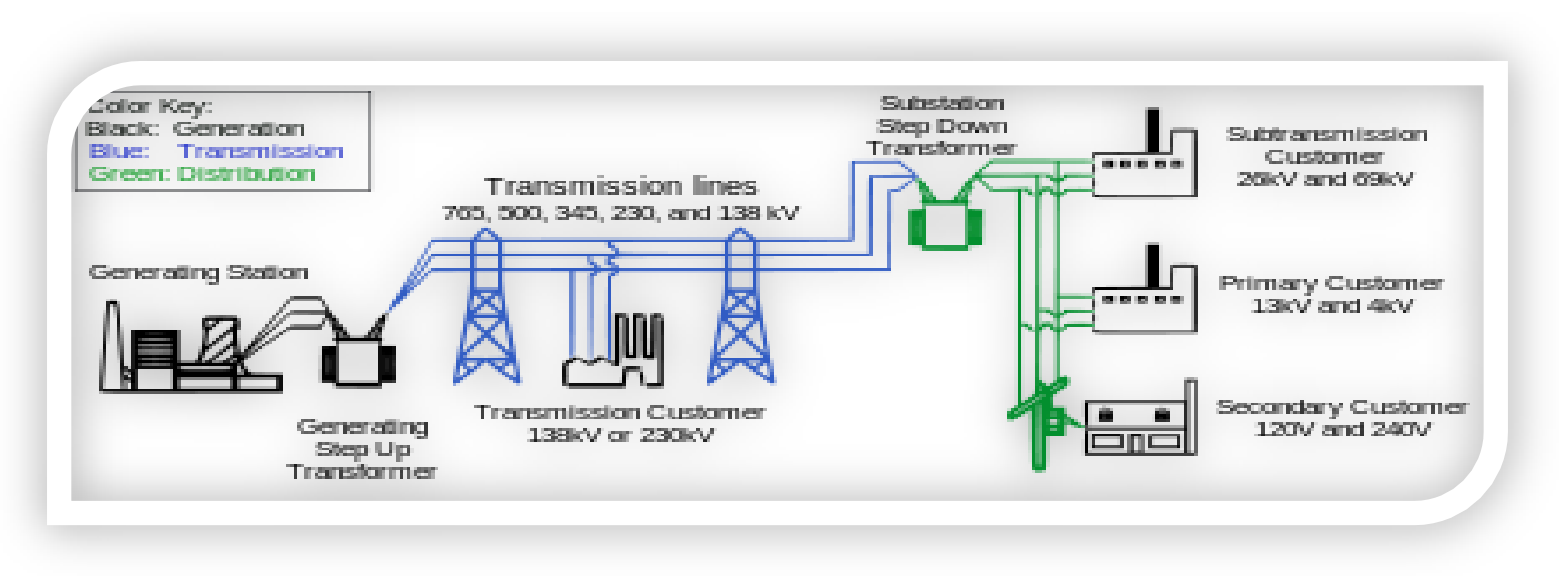

Figure 1. A typical electric power system.

times used in urban areas or sensitive locations. Substations transform voltage between high and low and perform related functions. Electric power may flow through several substations at different voltage levels from the generating station to the consumer. Transmission level voltages are usually $110 \mathrm{KV}$ and above, but lower voltages such as $66 \mathrm{KV}$ and $33 \mathrm{KV}$ are commonly used on long lines with street lights. Voltages less than $33 \mathrm{KV}$ are usually used for distribution while extra high voltages above $230 \mathrm{KV}$ need a different setup. At the power stations the power is produced at a relatively low voltage between $2.3 \mathrm{KV}$ and $30 \mathrm{KV}$. The generator terminal voltage is then stepped up by the power station transformer to a higher voltage (115 KV to $765 \mathrm{KV} \mathrm{AC}$ ) for long-distance transmission.

\section{Electromagnetic Radiation}

\subsection{Radiation Types}

The world suffers from electromagnetic contamination and electrosmog (e-smog). E-smog refers to the huge amount of electromagnetic fields (EMFs) present on this planet. Electrical and magnetic equipment cause esmog and produce invisible EMFs and EMR that constantly attack the human body affecting its biofield. EMR is categorized by frequency and falls into two types: non-ionizing which is the low-level radiation "mistakenly" perceived as harmless to humans, and ionizing which has a potential for cellular and DNA damage (Figure 2).

EMFs fall into these types [20]:

- Static electric fields caused by ions released from synthetic materials, and can make humans feel unwell.

- Residual magnetism that often occurs from metal in the bed and can change its magnetic field causing body discomfort.

- Power frequency fields from wall wiring, electrical outlets, extension cords, lighting and other electrical appliances. These may turn the body into an antenna and interfere with the ability of the cells to communicate with each other.

- Power frequency magnetic fields caused by faults in wiring, power lines running underground near the sleeping area, electrical panel boxes located on adjacent walls or even a refrigerator or TV located on the other side of a wall.

- Radio communication frequency fields that include a broad range of radio and TV, cordless phones, wireless devices, cell phones and communication towers.

- Radioactivity (and its by-product radon): This enters the home from building materials such as graniteone-third of the granite in homes is radioactive, and radon gas is emitted from the ground.

\subsection{Radiation Sources}

EMFs occur in nature but current environmental exposure to man-made sources of EMF has progressively increased due to the overwhelming use of electricity and wireless technologies [13]. A human body is exposed to a complex mix of EMFs at various frequencies during lifetime [19]. Table 1 lists some non-ionizing sources and the following are the main sources of high-voltage electricity radiation [24]: 


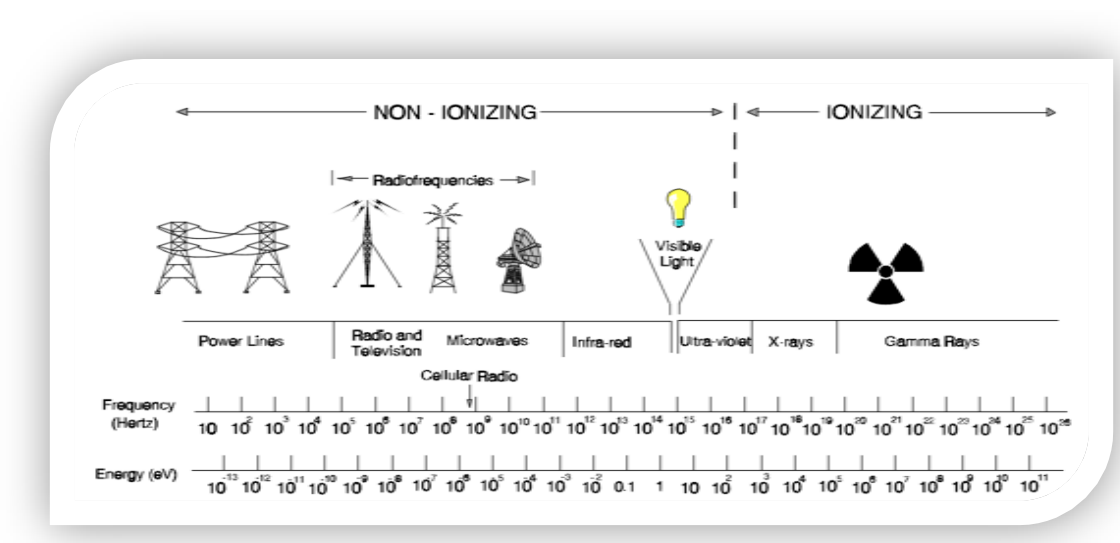

Figure 2. Ionizing and non-ionizing regions of the electromagnetic spectrum.

Table 1. Non-ionizing radiation.

\begin{tabular}{|c|c|c|c|}
\hline $\begin{array}{l}\text { Radiation } \\
\text { Type }\end{array}$ & Definition & Forms of Radiation & Source Examples \\
\hline Non-Ionizing & $\begin{array}{l}\text { Low to mid-frequency } \\
\text { radiation which is "generally } \\
\text { perceived" as harmless due to } \\
\text { its lack of potency. }\end{array}$ & $\begin{array}{ll}\bullet & \text { Extremely Low } \\
& \text { Frequency (ELF) } \\
- & \text { Radiofrequency (RF) } \\
\bullet & \text { Microwaves } \\
- & \text { Visual light }\end{array}$ & $\begin{array}{ll}\bullet & \text { Microwave ovens } \\
\bullet & \text { Computers } \\
\bullet & \text { House energy smart meters } \\
\bullet & \text { Wireless (WiFi) networks } \\
\bullet & \text { Cell phones } \\
- & \text { Bluetooth devices } \\
- & \text { Power lines } \\
- & \text { MRIs }\end{array}$ \\
\hline
\end{tabular}

- $\quad$ High-voltage power lines.

- $\quad$ District transmission lines.

- $\quad$ Lightning-protection systems.

- $\quad$ Grounding systems.

- Common electrical appliances, including microwave ovens, air conditioners, fans, electric heaters, electric blankets, hair dryers, etc.

- $\quad$ Appliances and power lines at extremely low frequencies (ELF).

\section{Field Measurements and Observations}

\subsection{Measuring Tools}

Electric field strength is measured in volts per meter $(\mathrm{V} / \mathrm{m})$. Magnetic fields are measured in units of gauss $(\mathrm{G})$ or tesla $(\mathrm{T})$, with $1 \mathrm{~T}=10,000 \mathrm{G}$, and most commonly in microtesla $(\mu \mathrm{T})$ or milligauss (mG). The sensor that was used in the measurements is the Cell Sensor EMF Detection Meter (Figure 3). It detects cell phone radiation and extremely low frequency electromagnetic fields as well as high strength signals, delivers audible and visual alerts, and includes a remote probe for ease of measurement. It measures hazards with an easy-to-read gauge that also beeps and glows when high readings are detected, runs on one 9-volt alkaline battery and has a flattened frequency response in ELF mode for increased accuracy.

\subsection{Exposure to EMFs}

Electric currents exist naturally in the human body and play an important role in the normal physiological functions [10]. Nerves transmit their signals by relaying electric impulses. The effects of exposure to EMFs on the body and cells depend on the EMF frequency and strength. At low frequency EMFs pass through the body, 


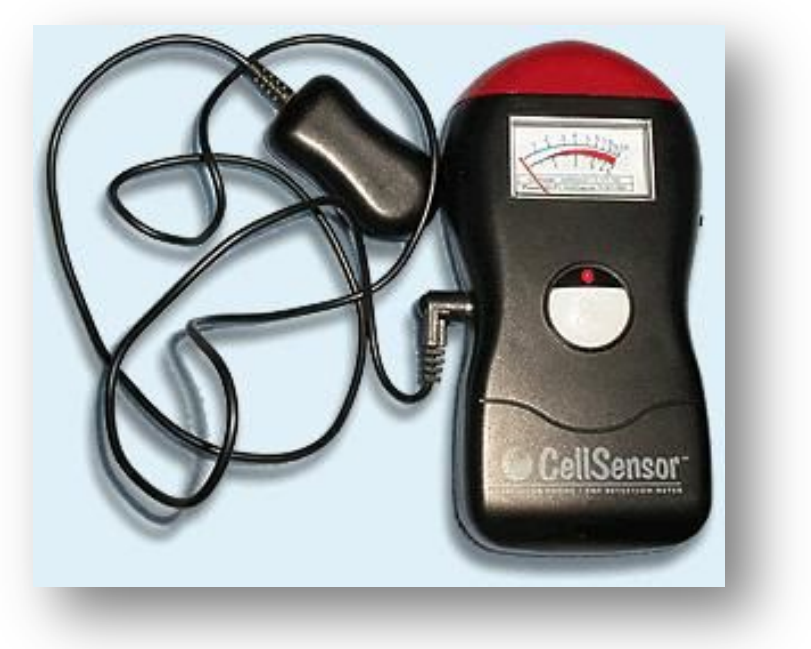

Figure 3. Measuring device.

while at radio frequencies the fields are partially absorbed and penetrate only a short depth into the tissue. Low-frequency electric fields influence the distribution of electric charges at the surface of conducting tissues and cause electric currents to flow in the body. Low-frequency magnetic fields induce circulating currents within the body; the strength of these induced currents depends on the amount of the external magnetic field and the size of the loop through which the current flows. When large enough, these currents can cause excitation of nerves and muscles [9].

\subsection{Exposure to $50 \mathrm{~Hz}$ Fields}

Magnetic fields within homes can vary greatly. Figure 4 shows some EMFs around power lines in a typical home [15] [17]. Nearby fields can penetrate 6 - 7 inches into the body, the safe exposure levels being [8]:

- $1 \mathrm{mG}$ or less: considered safe for sleepers.

- $\quad$ Above $2 \mathrm{mG}$ : start of creation of biological stress.

- $8 \mathrm{mG}$ : discomfort from electric blanket on low.

- $21 \mathrm{mG}$ : larger discomfort from electric blanket on high.

The safety limits specified by the USA Environmental Protection Agency [16] are shown in Table 2.

\subsection{Proximity to Overhead Lines}

The sites of the investigation are shown in Figure 5 and Figure 6. The strength of an EMF decreases dramatically with increasing distance from the source. This means that the strength of the field reaching a house or structure will be significantly weaker than it was at its origin. For example, a magnetic field measuring $57.5 \mathrm{mG}$ immediately beside a $230 \mathrm{KV}$ transmission line measures just $7.1 \mathrm{mG}$ at a distance of 100 feet, and $1.8 \mathrm{mG}$ at a distance of 200 feet. During the measurement, the selected sites A and C were found to contain old premises, and due to building expansion, the area was occupied by laborers and construction equipment employed to build a seven-storey building close to the high-voltage power line (HVPL). The HVPL is too close to the upper floor apartments and to the roofs of nearby buildings (Figure 7 and Figure 8). The measuring device was beeping high at these areas indicating that EMR strength exceeded the device scale limit. There were some buildings inside the critical zone of the power lines, in addition to some people parking their vehicles directly below the power lines. In site B most of the buildings are old, one to two-storey buildings. The main street that is going along with HVPL is occupied by a commercial market (restaurants, groceries, pharmacies, etc.). There is a petrol station and a junk yard with hundreds of people working and living right under the power lines.

\subsection{Measurements Mapping}

The location geographic coordinates were taken and the EMR strength at those points together with the vertical distance to the power line were measured (Table 3), and the locations were charted in a map to demonstrate the 


\begin{tabular}{|c|c|c|}
\hline EMF Source & $\begin{array}{c}\begin{array}{c}\text { Distance } \\
\text { (feet) }\end{array} \\
\end{array}$ & $\begin{array}{c}\begin{array}{c}\text { Strength } \\
(\mathrm{mG})\end{array} \\
\end{array}$ \\
\hline \multicolumn{3}{|c|}{ Common Appliances } \\
\hline \multirow{2}{*}{ Microwave Oven } & 0.5 & 200 \\
\hline & 1.0 & 4 \\
\hline \multirow{2}{*}{ Vacuum Cleaner } & 0.5 & 300 \\
\hline & 1.0 & 60 \\
\hline \multirow{2}{*}{ Power Drill } & 0.5 & 150 \\
\hline & 1.0 & 30 \\
\hline \multirow[b]{2}{*}{ Office copy Machine } & 0.5 & 90 \\
\hline & 1.0 & 20 \\
\hline \multirow{2}{*}{ Hair Dryer } & 0.5 & 300 \\
\hline & 1.0 & 1 \\
\hline \multirow{2}{*}{ Electric Shaver } & 0.5 & 100 \\
\hline & 1.0 & 20 \\
\hline \multicolumn{3}{|c|}{ Transmission Lines } \\
\hline \multirow{3}{*}{$115 \mathrm{kV}$} & 0 & 29.7 \\
\hline & 49 & 6.5 \\
\hline & 200 & 0.4 \\
\hline \multirow{3}{*}{$230 \mathrm{kV}$} & 0 & 57.5 \\
\hline & 49 & 19.5 \\
\hline & 200 & 1.8 \\
\hline
\end{tabular}
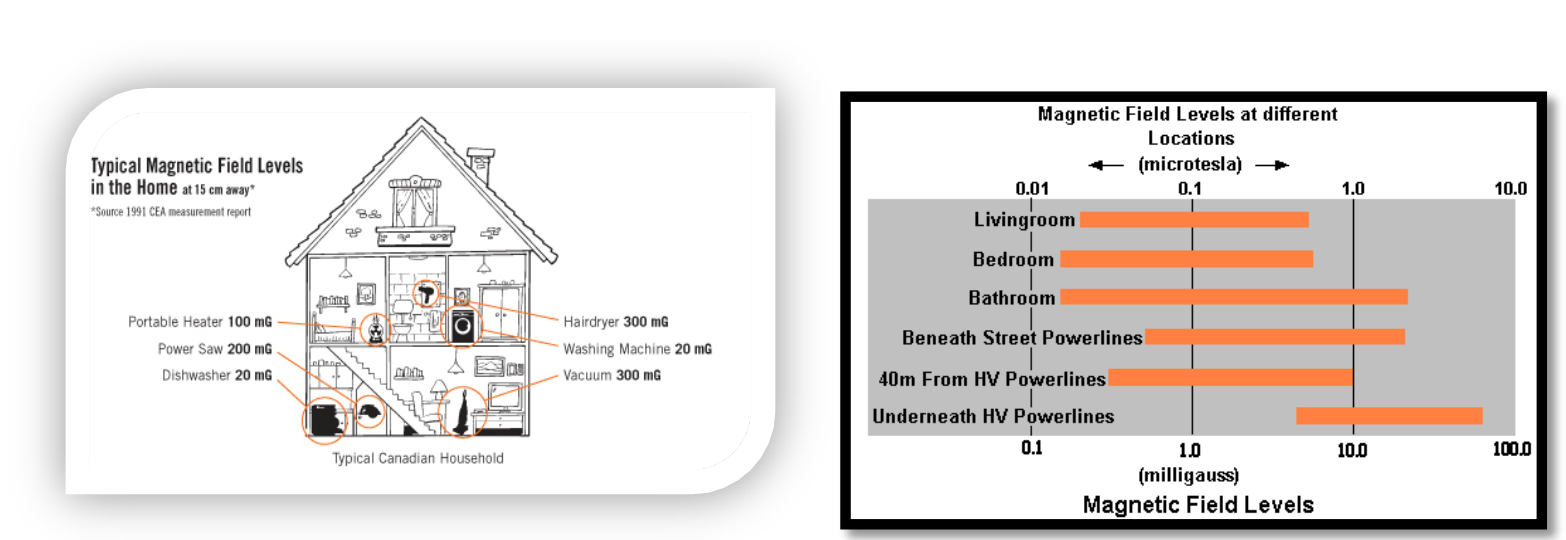

Figure 4. Typical EMF and EMR at home.

power lines, the points of the studied sites and the critical zones. There is no school or medical building within the high-power tower zones. The city has around 100 main power stations with primary voltage of $110 \mathrm{KV}$ for the underground power line, and $380 \mathrm{KV}$ for high-voltage transmission lines (HVTL) that are transformed to 13.8 KV in the secondary stations. There are more than 30,000 secondary stations that cover the city, initially with $13.8 \mathrm{KV}$ that is transformed into $110 / 220 \mathrm{~V}$ for public use. According to the EMR strength at the investigated sites the distance to approach the safe limit of $2 \mathrm{mG}$ is equivalent to 100 meters and above. The distances have been divided into four zones $(25,50,75,100 \mathrm{~m})$ to demonstrate the number of houses existing in each zone. 
Table 2. Safety limits for EMFs.

\begin{tabular}{ccc}
\hline \multicolumn{2}{c}{ Danger zones EMF levels from common sources in milligauss (mG) recommended safely levels $0.5 \mathrm{mG}-2.5 \mathrm{mG}$} \\
\hline Source & Up to 4 inches 3 feet \\
\hline Blender & 50 to 220 & 0.3 to 3 \\
Clothes Washer & 8 to 200 & 0.1 to 4 \\
Coffee Maker & 6 to 29 & 2 to 5 \\
Computer & 4 to 20 & 0.1 to 5 \\
Fluorescent Lamp & 400 to 4000 & 0.1 to 6 \\
Hair Dryer & 60 to 20000 & 1 to 25 \\
Microwave Oven & 100 to 500 & 0.1 to 6 \\
Television & 5 to 100 & 3 to 40 \\
Vacuum Cleaner & 230 to 1300 & $50 \mathrm{mG}$ avg. in a 747 \\
Airplane & &
\end{tabular}

Source: USA Environmental Protection Agency.

Table 3. High-voltage power lines coordinates and EMR at test sites.

\begin{tabular}{|c|c|c|c|c|c|}
\hline \multirow{2}{*}{ No. } & \multicolumn{2}{|c|}{ Coordinates } & \multirow{2}{*}{$\begin{array}{c}\text { EMR } \\
\mathrm{mG}\end{array}$} & \multirow{2}{*}{$\begin{array}{c}\text { Distance } \\
\mathrm{m}\end{array}$} & \multirow{2}{*}{ Description } \\
\hline & Longitude & Latitude & & & \\
\hline 1 & 39.24253 & 21.52213 & 40 & 30 & \\
\hline 2 & 39.24253 & 21.57217 & 40 & 30 & AQBM St. (Site A) \\
\hline 3 & 39.24470 & 21.57239 & 40 & 30 & \\
\hline 4 & 39.24478 & 21.57333 & $>1.3$ & 150 & NBAH St. (Site A) \\
\hline 5 & 39.24483 & 21.56861 & 40 & 30 & \\
\hline 6 & 39.24591 & 21.56851 & 40 & 20 & $\begin{array}{l}\text { IBH St. (Site C) 7-storey building } \\
\text { More than } 50 \mathrm{mG} \text { at the roof }\end{array}$ \\
\hline 7 & 39.24275 & 21.56912 & 40 & 20 & \\
\hline 8 & 39.24272 & 21.56707 & $>1.5$ & 180 & About 4 buildings and 2 streets distance \\
\hline 9 & 39.24871 & 21.56790 & $>4$ & 110 & About 4 buildings and 2 streets distance \\
\hline 10 & 39.14561 & 21.34238 & $>40$ & 60 & - \\
\hline 11 & 39.21840 & 21.64779 & $>50$ & 30 & Station \\
\hline 12 & 39.23001 & 21.63613 & $>50$ & 10 & City junk yard exactly below HVPL \\
\hline 13 & 39.22388 & 21.64022 & $>10$ & 50 & Commercial market \\
\hline 14 & 39.22465 & 21.64263 & $>1.5$ & 200 & Area with old buildings \\
\hline
\end{tabular}

A general note in this respect is that up to one-fifth of homes are covered in hot spots of electromagnetic fields over $2 \mathrm{mG}$. While it is safe to be in such a hot spot for a short time, it is not advisable to spend long periods in them, such as during sleeping hours. Most of these spots are small, so by locating them, the furniture can be safely moved out of these zones. It has also been noticed that there were no hazard warning signs or information regarding EMF and EMR issues in the publications that are available on the web or in the reports. The only concern was about the hazards of direct contact with overhead power lines, so the only communication to local municipalities was about the safety clearance guidelines [7] (Table 4). 
Table 4. Typical safety clearances. (a) Vertical clearances; (b) Horizontal clearances.

(a)

\begin{tabular}{|c|c|c|c|c|c|c|c|}
\hline \multirow{2}{*}{\multicolumn{2}{|c|}{ Construction type }} & Buildings & Telecom lines & Train road & High ways & Public ways & Agricultural roads \\
\hline & & \multicolumn{6}{|c|}{ Vertical clearances above the power line (height) in Meters } \\
\hline \multirow{4}{*}{ 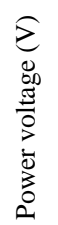 } & $69 \mathrm{kV}$ & 5 & 3 & 15 & 12 & 12 & 12 \\
\hline & $34.5 / 33 \mathrm{kV}$ & 4 & 2 & 8.5 & 12 & 7 & 6.7 \\
\hline & $13.8 \mathrm{kV}$ & 3 & 2 & 8.5 & 12 & 7 & 6.7 \\
\hline & Low power & 3 & 1.2 & 8.2 & 12 & 6 & 5 \\
\hline
\end{tabular}

(b)

\begin{tabular}{|c|c|c|c|c|c|c|}
\hline \multirow{2}{*}{\multicolumn{2}{|c|}{ Construction type }} & Buildings & Train road & High ways & Public ways & Agricultural roads \\
\hline & & \multicolumn{5}{|c|}{ Horizontal clearances side to power line in meters } \\
\hline \multirow{4}{*}{ 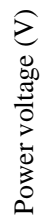 } & $69 \mathrm{kV}$ & 6.3 & 25 & 18 & 12 & 12 \\
\hline & $34.5 / 33 \mathrm{kV}$ & 2 & 15 & 15 & 12 & 12 \\
\hline & $13.8 \mathrm{kV}$ & 2 & 15 & 15 & 12 & 12 \\
\hline & Low power & 2 & 15 & 15 & 12 & 12 \\
\hline
\end{tabular}

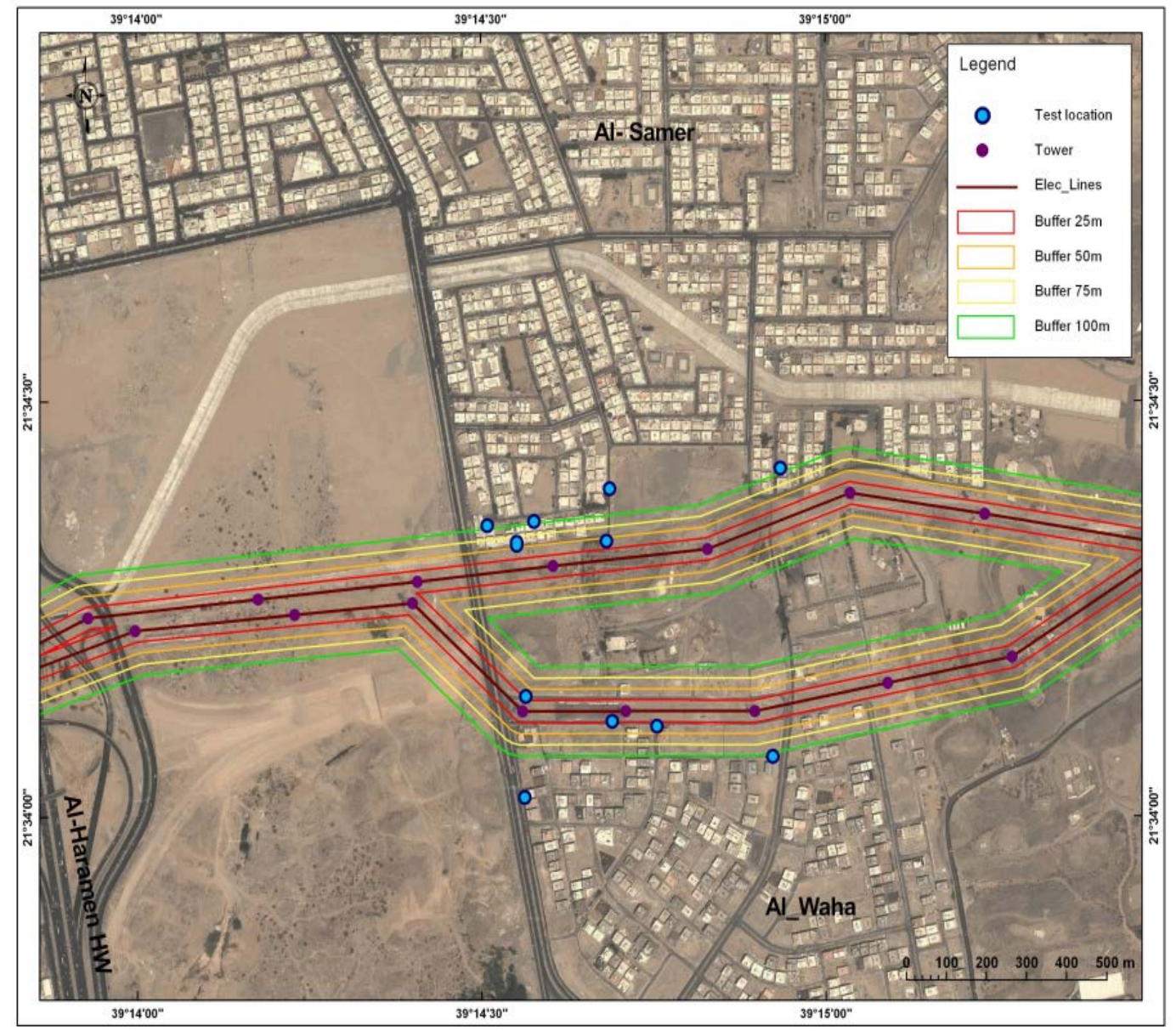

Figure 5. Sites A and C in the city. 


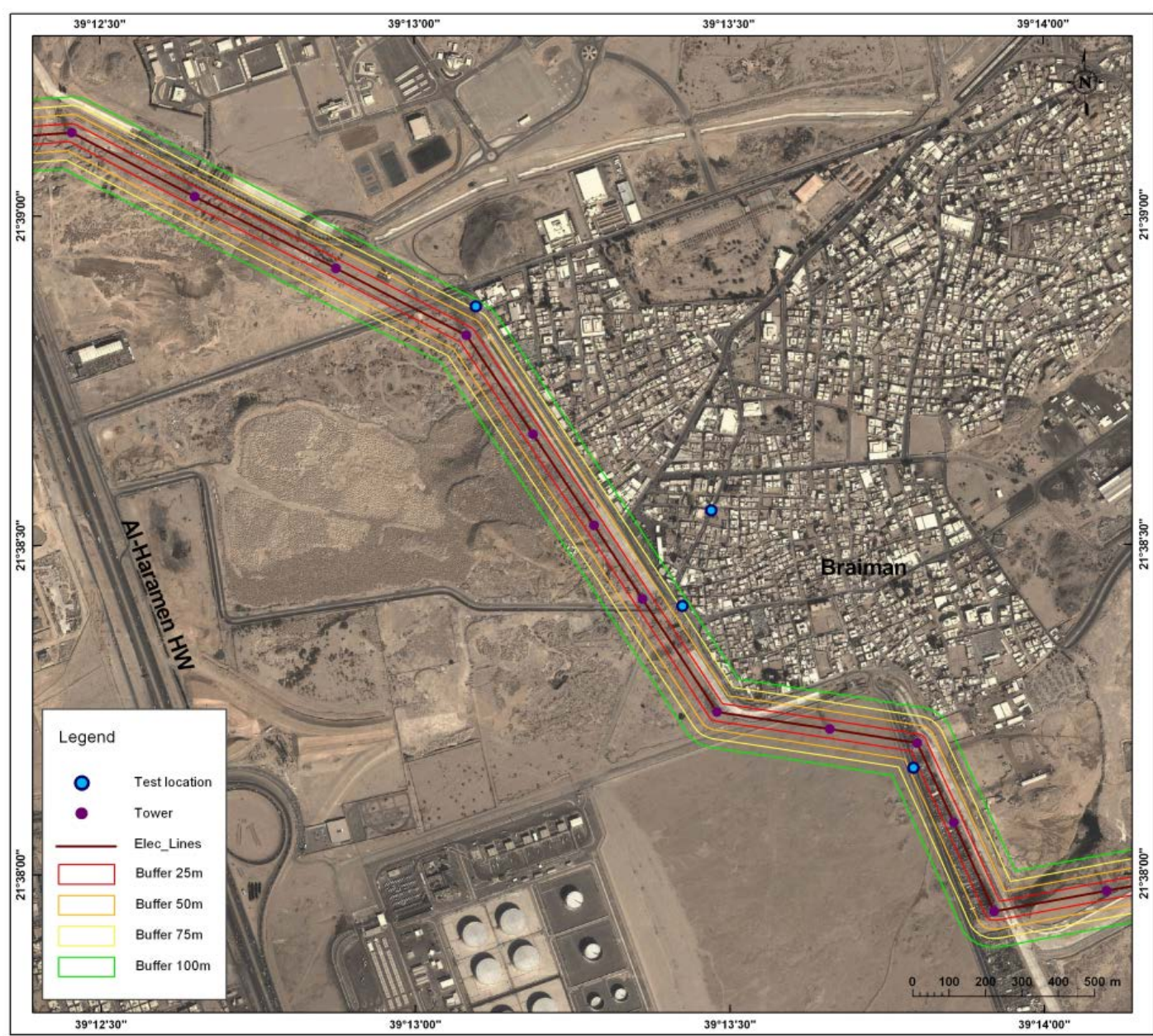

Figure 6. Site B in the city.

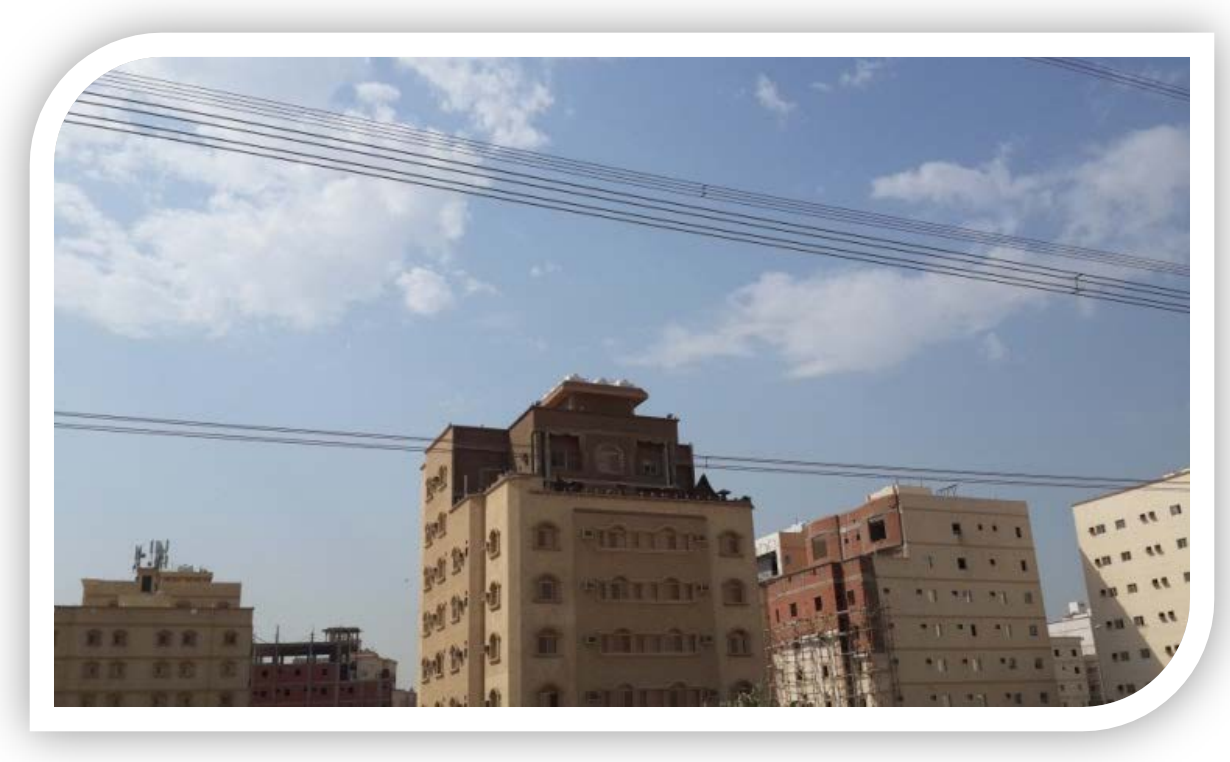

Figure 7. Proximity of power lines. 


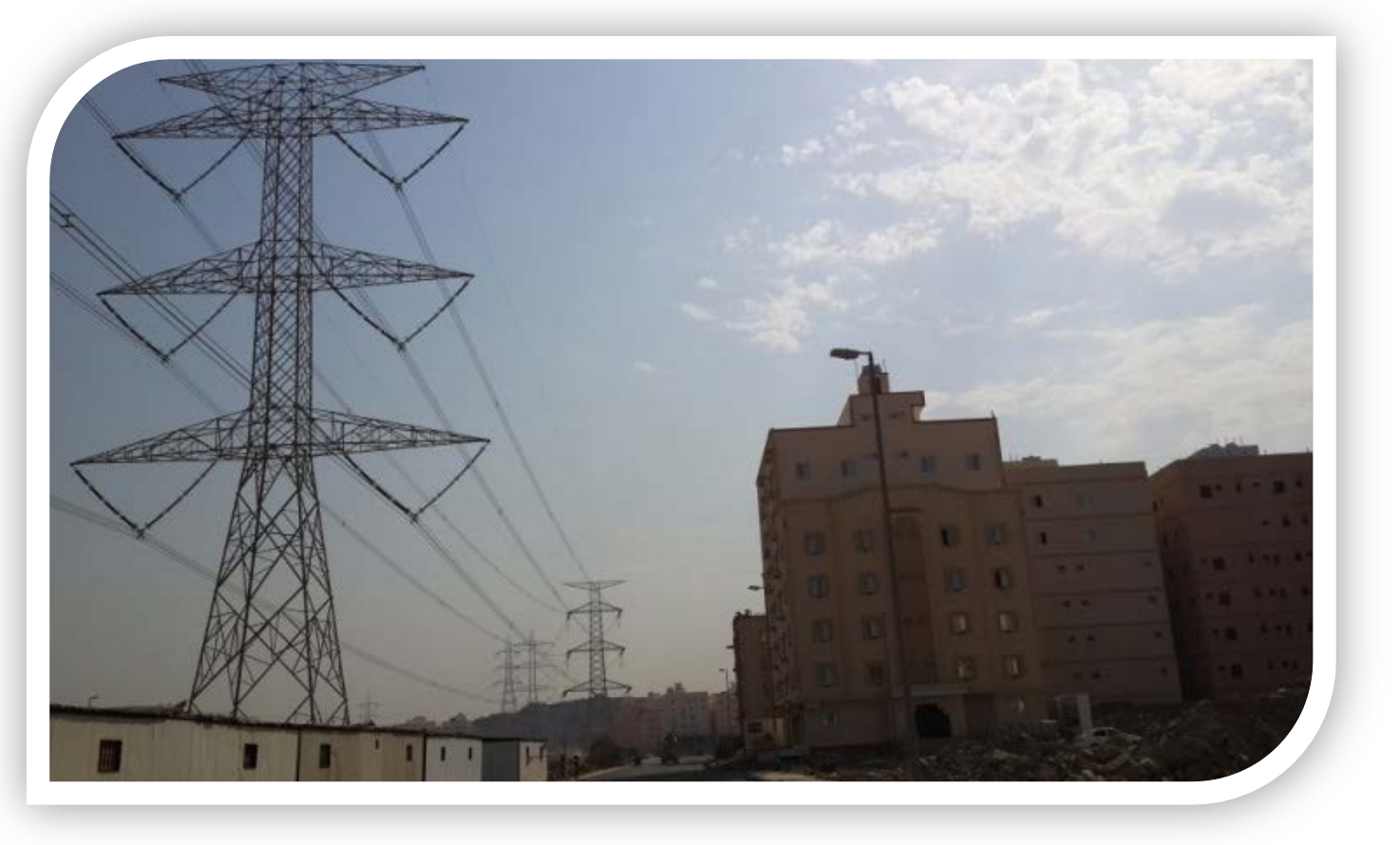

Figure 8. Proximity of high-voltage towers to nearby buildings.

\section{Hazards to Humans}

\subsection{Biological Effects}

Magnetic fields induce electric currents in electrical conductors including human, animal or plant bio-systems. E-smog creates an artificial stress situation in the bio-system which, in turn, affects the metabolism as well as hormone production. An individual's stress tolerance, which varies from person to person, determines the outbreak of an e-smog related disease. Adverse health effects manifest because the bio-system is exposed to technically-produced electromagnetic alternating fields which are many times stronger than the body's currents, and the frequency of which interferes and irritates the body's regulatory mechanism. When the body ages and lacks exercise and proper diet, the e-smog degenerates the weakness into sickness and disease. Biological effects are measurable reactions of the organisms or cells to a stimulus or to an environment change. However, the body might not own adequate compensation mechanisms to dampen all environmental changes or stresses. Health effects result from biological effects that cause deficiency in the health or wellbeing of exposed individuals when the energy of the fields is absorbed and transformed into movement of molecules. Temperature is raised because of friction between rapidly moving molecules [6]. Compliance with exposure limits recommended in international guidelines helps to control the risks of exposure [3] [4]. During the tests and according to locals, one strange medical condition happened with an inhabitant and exhibited in him perceiving things upside down accompanying any sudden movement he makes. A hospital practitioner attributed this and other similar cases in the area to suffering a previous head injury and living beside an EMF tower.

\subsection{Effects on Cells}

E-smog has an effect on cell physiology and consequently on the control mechanism of the body. EMFs produce reactions because cell communication happens at several thousandths, even millionths of a volt. For good health, the body must be able to communicate within itself, that is, to be in harmony with the natural rhythm. The random patterns from e-smog can create noise in the body and force it out of synchronization. The body is a complex communication system where cells, tissues, organs, and organisms all talk to each other; the communication includes finely tuned bio-electrical transmitters and receivers [1]. Two more well-known biological impacts of e-smog are the interruption of the brain wave patterns leading to behavioral complications, and the interfe- 
rence with the body's communication system (cytoskeleton) leading to unusual neurological function, such as dementia, chronic fatigue syndrome and fibromyalgia. The cell membrane receptors recognize EMFs at very low levels of exposure by producing a stress response similar to that produced by exposure to heavy metals or toxic chemicals. This can cause the cell membrane to go from an active or permeable state where it allows nutrients in and toxins out, to an inactive state where the cell membrane is impermeable. During the day, the cells will alternate states thousands of times, but the membranes can be locked in the inactive state under constant environmental stress. This is often referred to as "oxidative stress" as nutrients are able to enter into the cell, while toxins are not allowed to leave. There is evidence that the inactive state can even have geno-toxic effects, which means that e-smog is toxic and is damaging to the DNA and inhibits the body from repairing it. Table 5 represents diseases and health problems that are either a direct result of electromagnetic radiation or are closely associated with it. The limited studies that have been conducted on adults showed no conclusive proof of a link between EMF exposure and adult cancers [5]. Nevertheless, continuous education on practical ways of EMF exposure reduction is recommended [11].

\section{Conclusions and Recommendations}

Scientific knowledge about the health effects of EMFs is based on a large number of technological, epidemiological, animal and environmental studies. Many outcomes have been examined, but so far no conclusive evidence or connection has been drawn. This is due to overlooking the combined effects of multiple sources and the difficulty of correlating every effect with its cause, and because many of the effects are exhibited in the longterm surpassing the timescale of the technologies that caused them, and rendering any later investigation out of focus. A scientific working group of the WHO's International Agency for Research on Cancer (IARC) reviewed studies related to the carcinogenicity of static and extremely low frequency EMFs [21] [22]. Using the standard IARC classification that weighs up human, animal and laboratory evidence, ELF fields were classified as possibly carcinogenic to humans based on epidemiological studies of childhood leukemia. This classification is used to represent an agent for which there is limited evidence of carcinogenicity in humans and less than sufficient evidence for experimental animals [5]. Evidence for all other cancers in children and adults, as well as other types of exposures was considered inadequate to classify due to insufficient or inconsistent scientific information [2]. There is, however, some epidemiological evidence that prolonged exposure to higher levels (more than $0.4 \mu \mathrm{T}$ ) of power frequency magnetic fields is associated with a risk of leukemia in children [12].

It is obvious from our study that EMR does cause harmful effects on human health. EMF exposure has a cumulative effect, increasing over time and with the dose [23]. Children, pregnant women and those with poor health conditions are especially at risk for a lifetime of exposure [14]. The amount of "absorbed" vs. "exposed" radiation has to be considered since the absorption depends on the nature, amount and duration of radiation as well as the individual body condition. It is worth mentioning, however, that research and studies alerting from hazards are much more than those denying the effects. Communication and electricity industries and other par-

Table 5. Diseases associated with EMR.

\begin{tabular}{|c|c|c|c|}
\hline Child leukemia & Stress & Insomnia & Brain fog \\
\hline Breast cancer & Lupus & Forgetfulness & Brain cancer \\
\hline Immune dysfunction & Heavy metal toxicity & Birth defects & Heart problems \\
\hline Reduced sperm count & Brain tumors & $\mathrm{ADD} / \mathrm{ADHD}$ & Allergies \\
\hline Cancer & Alzheimer disease & Fatigue & Migraine \\
\hline Fibromyalgia & Inflammatory disease & Erratic pulse & Miscarriage \\
\hline Lyme disease & Poor concentration & Acoustic neuromas & Nausea \\
\hline Chest pain & Chronic fatigue & Parkinson disease & Rheumatoid arthritis \\
\hline Hypertension & Daily headaches & Ill health & Low iodine levels \\
\hline Digestive disorders & Asthma & Sleep disruption & Cell mutation \\
\hline \multicolumn{2}{|c|}{ Electromagnetic hypersensitivitiy (EHS) } & \multicolumn{2}{|c|}{ Diseases of the nervous system } \\
\hline
\end{tabular}


ties tend to mask the hazards in order not to risk their business, to the extent that some stakeholders stopped funding and sponsoring related research, while others are supporting research for opposing arguments. The research and studies that under-rate the effects argue that there is no dependable decisive evidence on the hazards, that most of the tests were carried out on animals giving results that do not reflect on humans, that the human body itself emits an electromagnetic power of 84 watt in the relax state and 10 times this amount in the active state, and that many people are exposed to high electromagnetic power over long periods without any noticeable effects on their health.

At the technical level it is recommended to replace the tower power lines with underground lines and to use the new technology of nano carbon tube for shielding the tower cables [18]. On the precautionary side it is recommended to stay away from the EMF sources and to increase the clearance to the limit of the sleeping safety zone. People should not sleep or sit for long periods near electrical devices, especially those containing motors. Beds or cribs should not be placed against walls with nearby major appliances. Electric appliances should be moved at least 4 feet away from the head of the bed. Fluorescent bulbs generate stronger fields than incandescent lamps and a distance of 1 foot for incandescent bulbs and 3 feet for fluorescent lamps should be observed. Electric blankets and hair blow dryers should be avoided.

\section{References}

[1] Adey, W.R. (1981) Tissue Interactions with Non-Ionizing Electromagnetic Fields. Physiological Reviews, 61, $435-514$.

[2] American Conference of Governmental Industrial Hygienists (2001) Documentation of the Threshold Limit Values and Biological Exposure Indices. 7th Edition, Publication No. 0100, Cincinnati.

[3] American National Standards Institute (ANSI) (1991) Safety Levels with Respect to Human Exposure to Radio Frequency Electromagnetic Fields, 3 kHz to 300 GHz. ANSI/IEEE C95.1-1991, Date of Publication 1992. http://ieeexplore.ieee.org/servlet/opac?punumber=2917

[4] American National Standards Institute. www.ansi.org

[5] Australian Radiation Protection and Nuclear Safety Agency. Electricity and Health. Fact Sheet 19. http://www.arpansa.gov.au/pubs/factsheets/019is_electricity.pdf

[6] Balzano, Q., Garay, O. and Steel, F.R. (1978) Energy Deposition in Simulated Human Operators of 800-MHz Portable Transmitters. IEEE Transactions on Vehicular Technology, 27, 174-181. http://dx.doi.org/10.1109/T-VT.1978.23746 .

[7] Dietrich, F.M. and Jacobs, W.L. (2001) Survey and Assessment of Electric and Magnetic Fields. Public Exposure in the Transportation Environment. US Department of Transportation, Federal Railroad Administration, Report No. PB99130908.

[8] Federal Communications Commission, Radio Frequency Safety, Web Report. www.fcc.gov/oet/rfsafety http://www.fcc.gov/encyclopedia/radio-frequency-safety

[9] IEEE Committee on Man and Radiation (COMAR), IEEE Engineering in Medicine and Biology Society (2000) Possible Hazards from Exposure to Power Frequency Electric and Magnetic Fields. 19, 131-137. http://ewh.ieee.org/soc/embs/comar/

[10] International Commission on Non-Ionizing Radiation Protection (ICNIRP) (1998) Latest Publications on Radio Frequency-EMF Guidelines, ICNIRP Guidelines for Limiting Exposure to Time-Varying Electric, Magnetic and Electromagnetic Fields. Health Physics, 74, 494-522.

[11] Kaune, W.T. (1993) Assessing Human Exposure to Power-Frequency Electric and Magnetic Fields. Environmental Health Perspectives, 101, 121-133. http://dx.doi.org/10.2307/3431668 ; http://dx.doi.org/10.1289/ehp.93101s473 http://dx.doi.org/10.1289/ehp.93101s4121

[12] Kaune, W.T. and Zaffanella, L. (1994) Assessing Historical Exposure of Children to Power Frequency Magnetic Fields. Journal of Exposure Analysis Environmental Epidemiology, 4, 149-170.

[13] Kovetz, A. (2000) Electromagnetic Theory. Clarendon Press.

[14] National Council on Radiation Protection and Measurements (1984) Some Issues Important in Developing Basic Radition Protection Recommendations. Proceedings of the 20th Annual Meeting, 4-5 April 1984. www.ncrp.com

[15] National Institute of Environmental Health Sciences (2002) Electric and Magnetic Fields Associated with the Use of Electric Power, Questions and Answers. NIEHS/DOE EMF RAPID Program. http://www.niehs.nih.gov/health/assets/docs_p_z/results_of_emf_research_emf_questions_answers_booklet.pdf

[16] NJ Dept Radiation Protection, Department of Environmental Protection. Radiation Protection and Release Prevention, 
$60 \mathrm{~Hz}$ Power Lines. www.state.nj.us/dep/rpp (Select Non-Ionizing Radiation) http://www.niehs.nih.gov/health/topics/agents/emf/ http://www.who.int/peh-emf/en/

[17] Office of Radiation, Radiation Studies Division (1992) EMF in Your Environment: Magnetic Field Measurements of Everyday Electrical Devices. US Environmental Protection Agency, Washington DC.

[18] Tarone, R.E., Kaune, W.T., Linet, M.S., Hatch, E.E., Kleinerman, R.A., Robison, L.L., Boice, J.D. and Wacholder, S. (1998) Residential Wire Codes: Reproducibility and Relation with Measured Magnetic Fields. US Environmental Protection Agency. Occupational and Environmental Medicine, 55, 333-339. http://dx.doi.org/10.1136/oem.55.5.333

[19] US Department of Transportation, NTIS (1999) Public Exposure in the Transportation Environment. Report of the Document PB99-130908. National Technical Information Service, Arlington, VA.

[20] Vanderlinde, J., (2004) Engineering in Medicine and Biology Society (1993) Classical Electromagnetic Theory. 2nd Edition, Wiley, New York.

[21] World Health Organization, Standards and Guidelines. Electromagnetic Fields (EMF). http://www.who.int/peh-emf/standards/en/

[22] World Health Organization EMF Project (2011: Lyon, France) Non-Ionizing Radiation, Part II: Radiofrequency Electromagnetic Fields/IARC Working Group on the Evaluation of Carcinogenic Risks to Humans, IARC Monographs on the Evaluation of Carcinogenic Risks to Humans. www.who.ch/peh-emf

[23] Department of Protection of the Human Environment, World Health Organization, Geneva, Switzerland (2002) Establishing a Dialogue on Risks from Electromagnetic Fields, Radiation and Environmental Health. http://www.who.int/peh-emf/publications/risk_hand/en/

[24] Zaffanella, L. (1993) Survey of Residential Magnetic Field Sources. Volume 1: Goals, Results and Conclusions. Electric Power Research Institute (EPRI), Palo Alto, CA, 1-224. 